\title{
Calidad fermentativa de ensilajes líquidos de chontaduro (Bactris gasipaes) tratados con yogur natural, suero de leche y melaza
}

\author{
Fermentative quality of liquid silage of peach palm (Bactris gasipaes) \\ treated with natural yoghurt, whey and molasses
}

\author{
Willan Orlando Caicedo ${ }^{1,2,3}$, Juan Carlos Moyano ${ }^{1}$, Segundo Benedicto Valle ${ }^{1}$, \\ Luis Antonio Díaz', María Eduarda Caicedo²
}

\section{Resumen}

\begin{abstract}
El estudio tuvo como objetivo evaluar los efectos de la adición de yogur natural, suero de leche y melaza en ensilajes líquidos de chontaduro (Bactris gasipaes) sobre indicadores físicoquímicos, biológicos y organolépticos para su uso en la alimentación animal. Se trabajó con tres ensilados utilizando la drupa madura de la planta: chontaduro con yogur natural (CYN), chontaduro con suero de leche (CSL), y chontaduro con suero de leche y melaza (CSLM). Se preparon 30 microsilos por tratamiento de un $1 \mathrm{~kg}$ cada uno que se evaluaron los días $1,4,8,15,30$ y 60 de iniciado el proceso de conservación (cinco por tratamiento). Las variables estudiadas fueron temperatura, $\mathrm{pH}$, presencia de bacterias (E. coli, Clostridium spp, Salmonella spp), olor, color y consistencia. Temperaturas más altas se encontraron en $\mathrm{CYN}\left(22.56^{\circ} \mathrm{C}\right)$ y $\operatorname{CSLM}\left(22.52^{\circ} \mathrm{C}\right)$ en el día $1, \mathrm{CYN}\left(22.48^{\circ} \mathrm{C}\right)$ y CSL $\left(22.42^{\circ} \mathrm{C}\right)$ en el día $15, \mathrm{CYN}\left(22.50^{\circ} \mathrm{C}\right)$ en el día 30 , y CYN $\left(22.46^{\circ} \mathrm{C}\right)$ y CSL $\left(22.34^{\circ} \mathrm{C}\right)$ en el día $60(\mathrm{p}<0.05)$. Los valores más altos de $\mathrm{pH}$ se observaron en CYN (4.82) en el día 1 y día 4 (4.49) con relación a los otros tratamientos $(\mathrm{p}<0.05)$. CSLM presentó el menor $\mathrm{pH}$ entre los días 8 y $60(4.19-4.17)(\mathrm{p}<0.05)$. No hubo presencia de las bacterias en estudio en ninguno de los tratamientos. Los ensilados presentaron olor dulce fermentado, color café amarillento y consistencia semidura en todas las evaluaciones. Los tres ensilados líquidos de drupa de chontaduro presentaron un comportamiento adecuado de los indicadores físicoquímicos, microbiológicos y organolépticos hasta el día 60, todos aptos para el consumo de animales.
\end{abstract}

Palabras clave: alimento alternativo; Bactris gasipaes; cerdos; fermentación líquida

\footnotetext{
${ }^{1}$ Departamento de Ciencias de la Tierra, Universidad Estatal Amazónica, Pastaza, Ecuador

${ }^{2}$ Granja Agropecuaria Caicedo, Puyo, Pastaza, Ecuador

${ }^{3}$ E-mail: orlando.caicedo@yahoo.es
}

Recibido: 10 de abril de 2018

Aceptado para publicación: 18 de noviembre de 2018 
The aim of this study was to evaluate the effects of the addition of natural yoghurt, whey and molasses in liquid silages of peach palm (Bactris gasipaes) on physicochemical, biological and organoleptic indicators for use in animal feed. Three silages were used using the mature drupe of the plant: peach palm with natural yogurt (CYN), peach palm with whey (CSL), and peach palm with milk whey and molasses (CSLM). Thirty microsilos were prepared per treatment of $1 \mathrm{~kg}$ each, which were evaluated on days $1,4,8,15,30$ and 60 of the start of the conservation process (five per treatment). The variables studied were temperature, $\mathrm{pH}$, presence of bacteria (E. coli, Clostridium spp, Salmonella spp), smell, color and consistency. Higher temperatures were found in CYN $\left(22.56^{\circ} \mathrm{C}\right)$ and $\operatorname{CSLM}\left(22.52^{\circ} \mathrm{C}\right)$ on day $1, \mathrm{CYN}\left(22.48^{\circ} \mathrm{C}\right)$ and $\operatorname{CSL}\left(22.42^{\circ} \mathrm{C}\right)$ on day $15, \mathrm{CYN}\left(22.50^{\circ} \mathrm{C}\right)$ on day 30 , and $\mathrm{CYN}\left(22.46^{\circ} \mathrm{C}\right)$ and $\operatorname{CSL}\left(22.34^{\circ} \mathrm{C}\right)$ on day $60(\mathrm{p}<0.05)$. The highest $\mathrm{pH}$ values were observed in $\mathrm{CYN}(4.82)$ on day 1 and day 4 (4.49) as compared to the other treatments $(\mathrm{p}<0.05)$. CSLM had the lowest $\mathrm{pH}$ between days 8 and 60 (4.19-4.17) $(\mathrm{p}<0.05)$. There was no presence of the bacteria under study in none of the treatments. The silages presented sweet fermented odor, yellowish brown color and semi-hard consistency in all evaluations. The three liquid silages of peach palm drupes presented adequate physicochemical, microbiological and organoleptic characteristics until day 60 , all suitable for animal feeding.

Key words: alternative feed; Bactris gasipaes; pigs; liquid fermentation

\section{INTRODUCCIÓN}

En Ecuador se produce una amplia gama de productos agrícolas para la alimentación humana, y se genera una alta tasa de alimentos que no cumplen los estándares para consumo de la población, y que no se aprovechan de forma adecuada para la alimentación animal (Caicedo et al., 2015). El uso de alimentos locales constituye una buena fuente de alimentos alternativos para los cerdos (Lezcano et al., 2017). Por otro lado, estos productos están disponibles en gran volumen, pero por su carácter perecedero, se limita su uso, y no se pueden aprovechar de forma eficiente en la alimentación porcina (Castro y Martínez, 2015). Entre estos, se encuentra la drupa del cultivar de chontaduro (Bactris gasipaes), fruta conocida como pupunha en Brasil, pijuayo en Perú y pijiguao en Venezuela (Valencia et al., 2012).
En las regiones tropicales y subtropicales de Ecuador, la drupa de chontaduro se produce en dos épocas del año (febreroabril y julio-septiembre), con buenos rendimientos y apreciable contenido de nutrientes, entre los que se destaca el contenido de grasa, proteína, almidón, fibra dietética, azúcares reductores, vitamina $\mathrm{C}$ y carotenoides (Arroyo y Murillo, 2014; Escobar et al., 2016). Sin embargo, la fruta, una vez cosechada, inicia un rápido proceso de descomposición por la acción de microorganismos putrefactivos, lo cual limita la vida útil de la drupa para su utilización en la alimentación de animales (Chaturvedi et al., 2013).

Este escenario permite utilizar la técnica de ensilaje líquido a través del uso de inóculos de bacterias acido lácticas (Lactobacillus plantarum, L. gasseri, L. acidophilus, L. rhamnosus [casei], Estreptococus termófilus, L. bulgaricus, 
Leuconostoc spp y Pediococcus spp) como una alternativa asequible para su uso en la alimentación de porcinos (Lezcano et al., 2015). Este proceso biotecnológico permite mantener un adecuado control del ácido láctico, $\mathrm{pH}$ y amoniaco $\left(\mathrm{NH}_{3}\right)$, para obtener un producto ensilado de óptima calidad nutricional, microbiológica y organoléptica, sin peligro de transmitir enfermedades para los animales (Wang et al., 2016).

El objetivo de este estudio fue evaluar los efectos de la adición de yogur natural, suero de leche y melaza sobre indicadores fisicoquímicos, biológicos y organolépticos de ensilajes líquidos de chontaduro (Bactris gasipaes) para su uso en la alimentación animal.

\section{Materiales y Métodos}

La investigación se realizó en las instalaciones de la «Granja Agropecuaria Caicedo», ubicada en la parroquia Tarqui, provincia de Pastaza, Ecuador. La zona tiene un clima semicálido o subtropical húmedo, con precipitaciones pluviales anuales entre 4000 y $4500 \mathrm{~mm}$, humedad relativa media de $87 \%$ y temperatura mínima y máxima promedio de 20 y $28{ }^{\circ} \mathrm{C}$ (IGM, 2016). Se encuentra a una altitud de $900 \mathrm{msnm}$.

En la preparación de los ensilajes (Cuadro 1) se siguieron los procedimientos de Caicedo (2015). Los microsilos se realizaron con drupa de chontaduro madura, las que por su apariencia física no cumplían las exigencias que establecen los consumidores, en cuanto a tamaño, forma y peso. Se adquirió un total de $120 \mathrm{~kg}$ de fruta de cinco días de poscosecha procedente del centro de acopio «San Jacinto» de la parroquia Tarqui. Los frutos fueron lavados en forma inmediata y molidos en forma fresca con un molino mixto, provisto de cuchillas y criba de $2.0 \mathrm{~cm}$, para obtener un tamaño de partícula uniforme. La melaza procedió de la central panelera «Tarqui». El yogur natural provino de la em-
Cuadro 1. Formulación de ensilados líquidos de chontaduro (Bactris gasipaes)

\begin{tabular}{lccc}
\hline \multirow{2}{*}{$\begin{array}{l}\text { Materias primas } \\
\text { (\%) }\end{array}$} & \multicolumn{3}{c}{ Tratamientos } \\
\cline { 2 - 4 } & CYN & CSL & CSLM \\
\hline $\begin{array}{l}\text { Chontaduro } \\
\text { maduro picado }\end{array}$ & 60 & 60 & 60 \\
Agua potable & 39 & - & - \\
Melaza & - & - & 5 \\
Yogur natural & 1 & - & - \\
Suero de leche & - & 40 & 35 \\
\hline Total & 100 & 100 & 100 \\
\hline
\end{tabular}

CYN: chontaduro con yogur natural

CSL: chontaduro con suero de leche

CSLM: chontaduro con suero de leche y melaza

presa «Toni S.A» de la red parroquia Puyo. El suero de leche se obtuvo en la quesería «Unión Libre» de la parroquia 10 de Agosto. La melaza se traslado a temperatura ambiente de $25^{\circ} \mathrm{C}$ en galones plásticos, mientras que el yogur natural y el suero de leche se transportaron en termos de acero inoxidable Mountain a $10^{\circ} \mathrm{C}$. El tiempo de traslado de las materias primas hacia las instalaciones de la «Granja Agropecuaria Caicedo» varió entre 10 y 15 minutos.

Las materias primas se pesaron en una balanza digital Camry, de $100 \mathrm{~kg}$ de capacidad y se depositaron en tres tanques plásticos, a razón de $50 \mathrm{~kg}$ de mezcla por recipiente. Cada tanque tenía una capacidad total para $100 \mathrm{~kg}$. El suero de leche y el yogur tenían una temperatura de $10{ }^{\circ} \mathrm{C}$ al momento de la preparación. Primero se colocó el chontaduro picado, y luego el resto de cada componente del tratamiento respectivo. Las mezclas se homogenizaron manualmente con una paleta de madera, durante 15 minutos y a temperatura ambiente $\left(24^{\circ} \mathrm{C}\right)$. Luego, se introdujeron en microsilos de polietileno con capacidad para $1 \mathrm{~kg}$, se cerraron y se almacenaron bajo techo y protegidos de la luz solar (Caicedo, 2013). Todos los silos se hicieron en una sola oportunidad. 
Cuadro 2. Descriptores para la valoración organoléptica de ensilajes de subproductos agrícolas

\begin{tabular}{llll}
\hline Atributo & Bueno (1) & Regular (2) & Malo (3) \\
\hline Olor & Dulce fermentado & Ácido suave & Pútrido \\
Color & $\begin{array}{l}\text { Gris claro, verdoso } \\
\text { claro, café amarillento }\end{array}$ & $\begin{array}{l}\text { Gris oscuro, verdoso } \\
\text { oscuro, café oscuro }\end{array}$ & Negruzco \\
Consistencia & Semidura, pastosa & Semilíquida & Líquida \\
\hline
\end{tabular}

Fuente: Caicedo y Valle (2016)

Los indicadores físicoquímicos (temperatura y $\mathrm{pH}$ ) se determinaron en 90 microsilos en los días $1,4,8,15,30$ y 60 del proceso de ensilaje, evaluándose cinco microsilos por tratamiento en cada oportunidad. La temperatura en los microsilos se midió a $20 \mathrm{~cm}$ de profundidad, con un termómetro digital Martini 2012 de precisión $\pm 0.5^{\circ} \mathrm{C}$ (Caicedo, 2013). Para la valoración del $\mathrm{pH}$ se utilizó extracto acuoso formado por una fracción de $25 \mathrm{~g}$ de ensilado y $250 \mathrm{ml}$ de agua destilada (Cherney y Cherney, 2003).

Se tomaron muestras al azar en nueve microsilos (tres por tratamiento) de los 15 utilizados en la determinación de los indicadores físico-químicos en cada día de conservación. En total se recolectaron 54 muestras, cada una de $200 \mathrm{~g}$ de ensilado, en frascos plásticos trasparentes estériles, con capacidad para 250 g. Se hizo el contaje de Escherichia coli, Clostridium spp y Salmonella spp, según los procedimientos de la AOAC (2003.01, Ed 20, 2016).

Las características organolépticas (olor, color y consistencia) se determinaron a los 4 , $8,15,30$ y 60 d de conservación (Cuadro 2), según Caicedo y Valle (2016). Se tomaron muestras al azar en 12 microsilos (cuatro por tratamiento) de los 15 microsilos evaluados en los diferentes tiempos de preservación. En total, se colectaron 60 muestras de $500 \mathrm{~g}$ cada una de ensilado en tarrinas plásticas de $1 \mathrm{~kg}$ de capacidad.

Los indicadores físicoquímicos y biológicos se evaluaron a través de un diseño completamente aleatorizado simple. El análisis de varianza se hizo de acuerdo a los procedimientos de Steel et al. (1997) y las medias se contrastaron por la prueba de Duncan (1955). Los análisis se hicieron con la aplicación del programa estadístico Infostat (Di Rienzo et al., 2012). Para valorar las características organolépticas (olor, color y consistencia) se hicieron diagramas de barras.

\section{Resultados}

No se notó aroma de alcohol ni síntoma de descomposición de los ensilajes al momento de la apertura de los microsilos. Los cambios de temperatura se muestran en el Cuadro 3. En el día uno, la temperatura del ensilado fue más alta en $\mathrm{CYN}\left(22.56^{\circ} \mathrm{C}\right) \mathrm{y}$ CSLM $\left(22.52^{\circ} \mathrm{C}\right)$ en comparación con CSL $\left(22.24^{\circ} \mathrm{C}\right)(\mathrm{p}<0.05)$. No obstante, las mediciones en los días 4 y 8 no revelaron diferencias entre tratamientos.

En el día 15, la temperatura del ensilaje fue mayor en CYN y CSL en comparación con CSLM $(p<0.05)$. La temperatura difirió significativamente entre los tres tratamientos 
Cuadro 3. Control de temperatura $\left({ }^{\circ} \mathrm{C}\right)$ en ensilados de chontaduro (Bactris gasipaes) durante los primeros 60 días de conservación (media, error estándar)

\begin{tabular}{|c|c|c|c|c|c|}
\hline \multirow{2}{*}{ Días } & \multicolumn{3}{|c|}{ Tratamientos $^{1}$} & \multirow{2}{*}{$\mathrm{EE} \pm$} & \multirow{2}{*}{ Valor de $\mathrm{p}$} \\
\hline & CYN & CSL & CSLM & & \\
\hline 1 & $22.56^{\mathrm{a}}$ & $22.24^{b}$ & $22.52^{\mathrm{a}}$ & 0.03 & $\mathrm{p}<0.0001$ \\
\hline 4 & 22.42 & 22.40 & 22.34 & 0.07 & $\mathrm{p}=0.7139$ \\
\hline 8 & 22.42 & 22.44 & 22.34 & 0.08 & $\mathrm{p}=0.6318$ \\
\hline 15 & $22.48^{\mathrm{a}}$ & $22.42^{\mathrm{a}}$ & $22.16^{\mathrm{b}}$ & 0.03 & $\mathrm{p}<0.0001$ \\
\hline 30 & $22.50^{\mathrm{a}}$ & $22.32^{\mathrm{b}}$ & $22.12^{\mathrm{c}}$ & 0.05 & $\mathrm{p}<0.0004$ \\
\hline 60 & $22.46^{\mathrm{a}}$ & $22.34^{\mathrm{a}}$ & $22.08^{\mathrm{b}}$ & 0.06 & $\mathrm{p}<0.0015$ \\
\hline
\end{tabular}

abc Medias con letra diferente en la misma fila difieren a $p<0.05$ (Duncan 1955)

${ }^{1} \mathrm{n}=5$ microsilos por tratatamiento por día de evaluación

Cuadro 4. Dinámica del pH en ensilados líquidos de chontaduro (Bactris gasipaes) durante los primeros 60 días de conservación (media, error estándar)

\begin{tabular}{|c|c|c|c|c|c|}
\hline \multirow{2}{*}{ Días } & \multicolumn{3}{|c|}{ Tratamientos $^{1}$} & \multirow{2}{*}{$\mathrm{EE} \pm$} & \multirow{2}{*}{ Valor de $p$} \\
\hline & CYN & CSL & CSLM & & \\
\hline 1 & $4.82^{\mathrm{a}}$ & $4.64^{\mathrm{b}}$ & $4.63^{b}$ & 0.01 & $\mathrm{p}<0.0001$ \\
\hline 4 & $4.49^{\mathrm{a}}$ & $4.34^{\mathrm{b}}$ & $4.23^{\mathrm{c}}$ & 0.01 & $\mathrm{p}<0.0001$ \\
\hline 8 & $4.45^{\mathrm{a}}$ & $4.33^{\mathrm{b}}$ & $4.19^{c}$ & 0.01 & $\mathrm{p}<0.0001$ \\
\hline 15 & $4.44^{\mathrm{a}}$ & $4.25^{\mathrm{b}}$ & $4.18^{c}$ & 0.01 & $\mathrm{p}<0.0001$ \\
\hline 30 & $4.44^{\mathrm{a}}$ & $4.24^{\mathrm{b}}$ & $4.18^{\mathrm{c}}$ & 0.04 & $\mathrm{p}<0.0001$ \\
\hline 60 & $4.44^{\mathrm{a}}$ & $4.23^{\mathrm{b}}$ & $4.17^{\mathrm{c}}$ & 0.01 & $\mathrm{p}<0.0001$ \\
\hline
\end{tabular}

abc Medias con letra diferente en la misma fila difieren a $p<0.05$ (Duncan 1955)

${ }^{1} \mathrm{n}=5$ microsilos por tratatamiento por día de evaluación

en el dia 30, siendo la mayor en CYN $(\mathrm{p}<0.05)$, mientras que en el día 60 se presentó una situación similar a la del día 15 , donde los ensilados CYN y CSL presentaron las mayores temperaturas $(\mathrm{p}<0.05)$.

El comportamiento del $\mathrm{pH}$ en ensilados líquidos de chontaduro se muestra en el Cuadro 4. El pH fue más alto al inicio de la fermentación en todos los tratamientos, donde CYN presentó el mayor valor $(\mathrm{p}<0.05)$. Entre los días 4 y 60 el pH se mostró estable para todos los ensilados, sin embargo, hubo diferencias significativas $(\mathrm{p}<0.05)$, pues el $\mathrm{pH}$ de CYN fue el más alto, seguido por CSL y CSLM respectivamente.

En los análisis microbiológicos no hubo presencia de Escherichia coli, Clostridium spp o Salmonella spp. Tampoco se encontraron diferencias en las características organolépticas de los ensilados líquidos de chontaduro. Los tres tratamientos presentaron características organolépticas idóneas 
$(100 \%)$ en cuanto a olor (dulce fermentado), color (café amarillento) y consistencia (pastosa).

\section{Discusión}

\section{Indicadores Fisicoquímicos}

Al inicio de la fermentación (día 1), los tratamientos CYN y CSLM presentaron la mayor temperatura en relación al tratamiento CSL. Varios estudios señalan que la variación de la temperatura al comienzo del proceso de fermentación se asocia con las células de las plantas que continúan respirando hasta que consumen todo el oxígeno presente en la materia prima vegetal. Simultáneamente, durante este proceso respiratorio se produce calor, agua y dióxido de carbono (Blanco-Valdes et al., 2016). Así también, en la superficie de los vegetales se encuentra un grupo de microflora epifítica (bacterias, hongos y levaduras) que generan una actividad microbiológica y enzimática produciendo calor hasta estabilizarse (Zahiroddini et al., 2004).

Por otra parte, la menor temperatura registrada en el tratamiento CSL pudo estar influenciada por la mayor concentración de bacterias ácido lácticas (BAL) presentes en el suero de leche en relación a los tratamientos que incluían agua con yogur natural CYN y suero de leche con melaza CSLM. Los inóculos al momento del inicio de la fermentación juegan un papel clave para el éxito del proceso de conservación de los ensilajes (Granados-Marín et al., 2014). Este hecho fue confirmando por Triana et al. (2014), quienes sometieron a un proceso de ensilaje a dos subproductos agroindustriales: cáscara de naranja y plátano de rechazo a través de la inoculación con Lactobacillus bucheneri proveniente del lactosuero y comprobaron la eficiencia del uso del inoculante en la reducción del tiempo de fermentación, y la estabilización de las variables temperatura, $\mathrm{pH}$, incremento del porcentaje de ácido láctico y crecimiento de $\mathrm{BAL}$ con mejoras en la calidad microbiológica y palatabilidad del ensilado.

La temperatura fue estable en los tres tratamientos entre los días 4 y 8 . Para controlar la temperatura de los silos y producir un ensilaje de buena calidad se requiere de la inoculación con BAL a un nivel mínimo de $10^{5} \mathrm{UFC} \mathrm{g}^{-1}$ de materia vegetal fresca (Wang et al., 2017). En este caso, la estabilidad de la temperatura puede atribuirse a que hubo una buena colonización de BAL aportadas por el yogur natural, el suero de leche y la melaza (Caicedo et al., 2016).

Al trascurrir el proceso de fermentación desde el día 15 hasta el 60, los ensilados CYN y CSL presentaron las temperaturas más altas con respecto a CSLM. En investigaciones realizadas en la Región Amazónica Ecuatoriana (RAE) por Caicedo et al. (2018), con ensilajes líquidos de banano orito con caña panelera tratados con yogur natural, melaza y suero de leche, encontraron diferencias significativas $(p<0.05)$ en temperatura entre tratamientos durante los 60 días de estudio; sin embargo, la diferencia entre tratamientos fue de $0.38^{\circ} \mathrm{C}$, siendo la temperatura registrada en los silos entre 22.41 y $22.79{ }^{\circ} \mathrm{C}$, resultados similares en correspondencia a los obtenidos en el presente estudio. La poca variación en la temperatura puede atribuirse a que no hubo actividad de microorganismos patógenos probablemente por la exclusión competitiva de las BAL desarrolladas en el medio (Caicedo et al. 2017). Por otra parte, si la temperatura en los silos cambia drásticamente se afecta la viabilidad y la actividad de acidificación de las BAL y se inhibe la síntesis proteica (Song et al., 2014), pues estas se desarrollan adecuadamente entre 15 y $25^{\circ} \mathrm{C}$. Además, este rango de temperatura ayuda a mantener el pH idóneo con valores de 3.9 a 4.3 para producir un buen ensilaje (Wang et al., 2017).

El mayor valor de $\mathrm{pH}$ de los ensilados se presentó en el día 1 de evaluación, especialmente en CYN. Esto se debe a que al 
inicio del proceso fermentativo la actividad de las BAL es reducida. Cambios en el pH depende de la cantidad de inóculos y carbohidratos solubles que se utilicen en los ensilados para que la población microbiana benéfica reduzca el $\mathrm{pH}$ rapidamente al aumentar las concentraciones de lactato y acetato (Ogiy et al., 2015; Graf et al., 2016; Ogunade et al., 2018). En este caso, CYN tenía en su formulación un alto contenido de $\mathrm{H}_{2} \mathrm{O}$ en relación con CSL que poseía una alta inclusión de suero de leche y CSLM suero de leche con melaza. En este sentido, hay reportes que informan que la inclusión de suero de leche y melaza en los ensilajes ayudan a a una reducción temprana del $\mathrm{pH}$ hasta lograr su estabilización (Granados-Marín et al., 2014).

Entre los días 4 y 60 el tratamiento con yogur natural, CYN tuvo los mayores valores de $\mathrm{pH}$. Al respecto, se evidenció que la utilización de suero de leche (CSL) y suero de leche con melaza (CSLM) redujeron más eficientemente el pH de los silos. Esto se debe a que el suero de leche contiene componentes como lactoalbúminas y lactoglobulinas ricas en aminoácidos de azufre (cisteína y metionina) y minerales. Las BAL usan el suero de leche para formar ácido láctico y la sacarosa de la melaza es convertida en glucosa y fructosa creando mejores condiciones para el desarrollo de Lactobacillus delbrueckii, L. helveticus y Streptomices thermophilus, microorganismos que ayudan a encontrar un rápido equilibrio del $\mathrm{pH}$ en los silos. Asimismo, un bajo $\mathrm{pH}$ permite hidrolizar los polisacáridos del material vegetal para que estén disponibles para las BAL (BautistaTrujillo et al., 2009; Li et al., 2016; Wanga et al., 2016).

El rápido control del $\mathrm{pH}$ en los ensilajes dentro de las primeras 96 horas de elaboración permite reducir las concentraciones de ácido butírico, nitrógeno amoniacal y el nivel de fibra bruta (Nkosi y Meeske, 2010). La disminución de la pared celular asegura un beneficio en el consumo del alimento y una reducción en su efecto de llenado físico en los animales (Holland et al., 1995). Por otra parte, la pronta estabilización del pH en los ensilados permite conseguir una buena estabilidad aeróbica (da Silva et al., 2018) para restringir el desarrollo de enzimas proteolíticas, clostridios y enterobacterias que ocasionan daños en los ensilados (Álvarez et al., 2015).

\section{Evaluación Microbiológica}

En todos los ensilados hubo ausencia de Escherichia coli, Clostridium spp y Salmonella spp. Este efecto puede atribuirse a que el uso de BAL como conservantes en la industria de alimentos promueven la producción de sustancias antimicrobianas que contribuyen favorablemente a la conservación de los alimentos por su capacidad para inhibir el crecimiento de microorganismos patógenos y descomponedores presentes en las materias primas (Agudelo et al., 2015; Zhang et al., 2018).

En procesos de fermentación adecuados, los azúcares se convierten en ácidos orgánicos, principalmente ácido láctico y acético que son los responsables de la rápida caída del $\mathrm{pH}$. En este medio se reduce la supervivencia de mohos, levaduras y clostridios, causantes de grandes pérdidas en los silos (Filya y Sucu, 2010; Santos et al., 2015). Así también, las BAL se utilizan en la industria alimentaria para preservar y mejorar las propiedades sensoriales de los alimentos; sus metabolitos como el peróxido de hidrógeno $\left(\mathrm{H}_{2} \mathrm{O}_{2}\right)$ y otros procedentes del metabolismo del oxígeno, así como compuestos aromáti$\cos$ (diacetilo, acetaldehido), derivados deshidratados del glicerol (reuterina), bacteriocina, diploccocinas, lactalinas y acidofilinas pueden inhibir el crecimiento de Salmonella spp, Listeria monocytogenes, Escherichia coli y Staphylococcus aureus (Fernández et al., 2014; Li et al., 2015). Por otra parte, los ensilajes mal conservados pueden ser una fuente de micotoxinas (deoxinivalenol y zearalenona), provocadas por el acceso de aire a los silos (Kalac, 2011). 


\section{Características Organolépticas}

Los tres ensilados presentaron olor dulce fermentado, color café amarillento y consistencia semidura. Resultados similares han sido reportados por Caicedo (2015) en ensilados de tubérculos de taro (Colocasia esculenta) hasta el día 30 de conservación. En forma similar, Caicedo et al. (2017) reportó resultados adecuados en ensilados de banano verde tratados con yogur natural, suero de leche y melaza. Es posible que la fermentación adecuada de los ensilajes, producto de una buena inoculación con BAL, limiten la producción de ácido butírico y, con esto, se favorezca el desarrollo de características organolépticas idóneas en los ensilados (Nkosi et al., 2016), así como un deterioro más lento del ensilado luego de ser expuestos al aire (Rodríguez et al., 2016).

En condiciones de un buen almacenamiento, las bacterias iniciadoras o BAL, además de la producción de ácido láctico para estabilizar el $\mathrm{pH}$, contribuyen con el sabor, aroma y textura de los ensilajes, y modifican las proteínas, debido a su actividad metabólica sobre proteínas, azúcares y lípidos (Arribas y Polo, 2008; Pescuma et al., 2008; Lyimo et al., 2016).

Algunos tipos de BAL pertenecientes a los géneros Lactobacillus, Leuconostoc y Weissella, son capaces de producir diversos exopolisacáridos (dextrano, levan, $\beta$-glucano) que inciden sobre las propiedades reológicas, químicas y sensoriales de los alimentos (Li et al., 2014; Leroy y Vuyst, 2016). La formación de dextrano de baja ramificación influye sobre el espesor, mientras que la producción de $\beta$-glucano se relaciona con la elasticidad. El dextrano de baja ramificación que producen las cepas Weissella confusa y Leuconostoc lactis produce una textura espesa acompañada de un olor y sabor agradable de los alimentos (Juvonen et al., 2015).

\section{Conclusión}

Los tres ensilados líquidos de drupa de chontaduro presentaron un comportamiento idóneo de los indicadores físicoquímicos, microbiológicos y organolépticos hasta el día 60 , todos aptos para el consumo animal.

\section{Literatura Citada}

1. Agudelo N, Torres-Taborda MM, Álvarez-López C, Vélez-Acosta LM. 2015. Bacteriocinas producidas por bacterias ácido lácticas y su aplicación en la industria de alimentos. Revista Alimentos Hoy 23: 186-205.

2. Álvarez S, Méndez P, MartínezFernández A. 2015. Fermentative and nutritive quality of banana by-product silage for goats. J Appl Anim Res 43: 396-401. doi: 10.1080/09712119.2014.978782

3. [AOAC] Association of Official Agricultural Chemists. 2016. 2003.01, Ed 20, 2016. Official methods of analysis of AOAC International. $20^{\text {th }} \mathrm{ed}$. Rockville, MD, USA: AOAC International. [Internet]. Available in: http://www.directtextbook.com/isbn/ 9780935584875

4. Arribas M, Polo C. 2008. Ocurrence of lactic acid bacteria and biogenic amines in biologically aged wines. Food Microbiol 25: 875-881. doi: 10.1016/ j.fm.2008.05.004

5. Arroyo C, Murillo M. 2014. Evaluación de la harina de pejibaye (Bactris gasipaes) en dietas para gansos durante el período de inicio. Nutr Anim Trop 8: 10-23.

6. Bautista-Trujillo GU, Cobos MA, Ventura-Canseco LM, Ayora-Talavera T, Abud-Archila M, Oliva-Llaven MA, Dendooven L, et al. 2009. Effect of sugarcane molasses and whey on silage quality of maize. Asian J Crop Sci 1: 3439. doi: 10.3923/ajcs.2009.34.39 
7. Blanco-Valdes Y, Durañona H, Acosta R. 2016. Efecto de la temperatura y la humedad en la conservación de granos de maíz en silos metálicos refrigerados. Cultivos Tropicales 37: 105-114. doi: 10.13140/RG.2.2.13900.21127

8. Caicedo WO. 2013. Potencial nutritivo del ensilado de tubérculos de papa china (Colocasia esculenta (L) Schott) para la alimentación de cerdos. Tesis de Maestría. Bayamo, Cuba: Univ. de Granma. 60 p.

9. Caicedo WO. 2015. Valoración nutritiva del ensilado de tubérculos de papa china (Colocasia esculenta (L) Schott) y su uso en la alimentación de cerdos en crecimiento ceba. Tesis Doctoral. Bayamo, Cuba: Univ. de Granma. 100 p.

10. Caicedo W, Valle S. 2016. Ensilaje líquido de subproductos agrícolas para la alimentación animal. Alemania: Ed Académica Española. $60 \mathrm{p}$.

11. Caicedo W, Rodríguez $R$, Lezcano $P$, Ly J, Valle $S$, Flores L, Ferreira FNA. 2015. Chemical composition and in vitro digestibility of silages of taro (Colocasia esculenta (L) Schott) tubers for feeding pigs. Cuban J Agr Sci 49: 59-64.

12. Caicedo W, Rodríguez $R$, Lezcano $P$, Ly J, Valle S, Flores L, Ferreira F. 2016. Physicochemical and biological indicators in silages of taro (Colocasia esculenta (L) Schott) tubers for animal feeding. Cuban J Agr Sci 50: 121-129.

13. Caicedo W, Vargas JS, Uvidia $H$, Samaniego E, Valle S, Flores L, Moyano $J$, et al. 2017. Physicochemical, biological and organoleptic indicators in banana silage (Musa sapientum) for pig feeding. Cuban J Agr Sci 51: 85-92.

14. Caicedo W, Flores A, Caicedo $M$. 2018. Indicadores fermentativos de ensilajes de banano orito (Mussa acuminata AA) con caña panelera (POJ93) para la alimentación porcina. REDVET 19(5). [Internet]. Disponible en: http://www.veterinaria.org/revistas/ redvet/n050518/051806.pdf
15. Castro M, Martínez M. 2015. La alimentación porcina con productos no tradicionales: cincuenta años de investigaciones en el Instituto de Ciencia Animal. Cuban J Agr Sci 49: 189-196.

16. Chaturvedi M, Kumar V, Singh D, Kumar S. 2013. Assessment of microbial load of some common vegetables among two different socioeconomic groups. Int Food Res J 20:2927-2931.

17. Cherney JH, Cherney DJR. 2003. Assessing silage quality. In: Buxton DR, Muck RE, Harrison JH (eds). Silage science and technology, Wisconsin, USA: American Society of Agronomy. p 141-198.

18. da Silva NC, Nascimento CF, Nascimento FA, de Resende FD, Daniel JLP, Siqueira GR. 2018. Fermentation and aerobic stability of rehydrated corn grain silage treated with different doses of Lactobacillus buchneri or a combination of Lactobacillus plantarum and Pediococcus acidilactici. J Dairy Sci 101: 4158-4167. doi: 10.3168/jds.2017-13797

19. Di Rienzo JA, Casanoves F, Balzarini MG, González L, Robledo CW. 2012. InfoStat v. 2012. [Internet]. Available in: http://www.infostat.com.ar/

20. Duncan DB. 1955. Multiple range and multiple F tests. Biometrics 11: 1-42. doi: 10.2307/3001478

21. Escobar J, Asanza M, Herrera B, González J. 2016. Caracterización físico-química de harinas de especies vegetales para la agroindustria ecuatoriana. Rev Amazónica Cienc Tecnol 5: 159-168.

22. Fernández KJ, Chanci IC, Wilches L, Cardona JA. 2014. Caracterización de los metabolitos de bacterias ácido lácticas y efecto inhibidor de las bacteriocinas en microorganismos patógenos en alimentos: revisión sistemática de la literatura, 2008-2012. Rev Biosalud 13: 45-61.

23. Filya I, Sucu E. 2010. The effects of lactic acid bacteria on the fermentation, aerobic stability and nutritive value of maize silage. Grass Forage Sci 65: 446-455. doi: 10.1111/j.1365-2494.2010.-00763.x 
24. Graf K, Ulrich A, Idler C, Klocke M. 2016. Bacterial community dynamics during ensiling of perennial ryegrass at two compaction levels monitored by terminal restriction fragment length polymorphism. J Appl Microbiol 120: 1479-1491. doi: 10.1111/jam.13114

25. Granados-Marín C, Ching-Jones R, Rojas-Bourrillón, A. 2014. Ensilaje de pasto estrella africana (Cynodon nlemfuensis) con la adición de melaza, suero de leche e inóculos microbiales. Cuadernos de Investigación UNED 6: 47-56.

26. Holland C, Kezar W, Quade Z. 1995. The pioneer forage manual. A nutricional guide. Des Moines, Iowa, USA: Pioner Hi-Bred International, Inc.

27. [IGM] Instituto Geográfico Militar. 2016. Geo visualizador. [Internet]. Disponible en: http://www.geoportaligm.gob.ec/portal/index.php/visualizador/

28. Juvonen R, Honkapää K, Maina NH, Shi Q, Viljanen K, Maaheimo $H$, Virkki L, et al. 2015. The impact of fermentation with exopolysaccharide producing lactic acid bacteria on rheological, chemical and sensory properties of pureed carrots (Daucus carota L). Int J Food Microbiol 17: 109-118. doi: 10.1016/j.ijfoodmicro.2015.04.031

29. Kalac P. 2011. The effects of silage feeding on some sensory and health attributes of cow's milk: a review. Food Chem 125: 307-317. doi: 10.1016/ j.foodchem.2010.08.077

30. Leroy F, Vuyst LD. 2016. Advances in production and simplified methods for recovery and quantification of exopolysaccharides for applications in food and health. J Dairy Sci 99: 32293238. doi: 10.3168/jds.2015-9936

31. Lezcano P, Martínez M, Vázquez A, Pérez O. 2017. Main methods of processing and preserving alternative feeds in tropical areas. Cuban experience. Cuban J Agr Sci 51: 1-10.

32. Lezcano P, Vázquez, A, Bolaños A, Piloto JL, Martínez M, Rodríguez $Y$. 2015. Ensilado de alimentos alternativos, de origen cubano, una alternativa técni- ca, económica y ambiental para la producción de carne de cerdo. Cuban J Agr Sci 49: 65-68.

33. Li C, Li W, Chen X, Feng M, Rui X, Jiang M, Dong M. 2014. Microbiological, physicochemical and rheological properties of fermented soymilk produced with exopoly-saccharide (EPS) producing lactic acid bacteria strains. Food Sci Technol-Leb 57: 477-485. doi: 10.1016/j.lwt.2014.-02.025

34. Li D, Ni K, Pang H, Wang Y, Cai Y, Jin Q. 2015. Identification and antimicrobial activity detection of lactic acid bacteria isolated from corn stover silage. Asian Austral J Anim 28: 620-631. doi: 10.5713 /ajas.14.0439

35. Li X, Xu W, Yang J, Zhao H, Pan $C$, Ding $X$, Zhang $Y$. 2016. Effects of applying lactic acid bacteria to the fermentation on a mixture of corn steep liquor and air-dried rice straw. Anim Nutr 2: 229-233. doi: 10.1016/j.aninu.2016.04.003

36. Lyimo BJ, Mtengeti EJ, Urio NA, Ndemanisho EE. 2016. Effect of fodder grass species, wilting and ensiled amount in shopping plastic bags on silage quality. Livestock Res Rural Develop 28(8). [Internet]. Available in: http:// www.lrrd.org/lrrd28/8/lyim28142.html

37. Nkosi BD, Meeske R. 2010. Effects of whey and molasses as silage additives on potato hash silage quality and growth performance of lambs. S Afr J Anim Sci 40: 229-237.

38. Nkosi BD, Meeske R, Langa T, Motiang MD, Modiba $S$, Mutavhatsindi TF, Malebana IM, et al. 2016. Effects of bacterial inoculation on the fermentation characteristics and aerobic stability of ensiled whole plant soybeans (Glycine max (L) Merr). S Afr J Anim Sci 46: 129-138. doi: 10.4314/ sajas.v46i2.3

39. Ogiy S, Chen Y, Pasvolsky R, Weinberg ZG, Moshe M. 2015. High resolution melt analysis to confirm the establishment of Lactobacillus plantarum and Enterococcus faecium from 
silage inoculants during ensiling of wheat. Grass1 Sci 62: 29-36. doi: 10.1111/ grs. 12102

40. Ogunade IM, Jiang Y, PechCervantes A, Kim DH, Oliveira AS, Vyas D, Weinberg ZG, et al. 2018. Bacterial diversity and composition of alfalfa silage as analyzed by Illumina MiSeq sequencing: effects of Escherichia coli $\mathrm{O} 157: \mathrm{H} 7$ and silage additives. J Dairy Sci 101: 2048-2059. doi: $10.3168 /$ jds.2017-12876

41. Pescuma M, Hebert EM, Mozzia F, de Valdez G. 2008. Whey fermentation by thermophilic lactic acid bacteria: evolution of carbohydrates and protein content. Food Microbiol 25: 442-451. doi: 10.1016/j.fm.2008.01.007

42. Rodríguez AA, Acosta Y, Rivera V, Randel PF. 2016. Effect of a microbial inoculantion fermentation characteristics, aerobic stability, intake, and digestibility of corn silage by rams. Rev Colomb Cienc Pec 29: 108-118.

43. Santos AO, Avila CL, Pinto JC, Carvalho BF, Dias DR, Schwan RF. 2015. Fermentative profile and bacterial diversity of corn silages inoculated with new tropical lactic acid bacteria. J Appl Microbiol 120: 266-279. doi: 10.1111/ jam. 12980

44. Song S, Bae DW, Lim K, Griffiths $M W, O h S$. 2014. Cold stress improves the ability of Lactobacillus plantarum 167 to survive freezing. Int J Food Microbiol 191: 135-143. doi: 10.1016/ j.ijfoodmicro.2014.09.017

45. Steel RGD, Torrie JH, Dickey M. 1997. Principles and procedures of statistics. A biometrical approach. $3^{\text {rd }} \mathrm{ed}$. New York, USA: MacGraw-Hill. 666 p.

46. Triana E, Leal F, Campo Y, Lizcano H. 2014. Evaluación de ensilaje a partir de dos subproductos agroindustriales (cáscara de naranja y plátano de recha- zo) para alimentación de ganado bovino. Revista Alimentos Hoy 22: 33-45.

47. Valencia $R$, Montúfar $R$, Navarrete $H$, Balslev H. 2012. Palmas ecuatorianas: biología y uso sostenible. Quito, Ecuador: Herbario de la QCA de la Pontificia Universidad Católica del Ecuador. 23 p.

48. Wang J, Chen L, Yuan X, Guo G, Li J, Bai Y, Shao T. 2016. Effects of molasses on the fermentation characteristics of mixed silage prepared with rice straw, local vegetable byproducts and alfalfa in southeast China. J Integr Agr 15: 653-670. doi: 10.1016/ S2095-3119(16)61473-9

49. Wang S, Yuan X, Dong Z, Li J, Shao T. 2017. Isolating and evaluating lactic acid bacteria strains for effectiveness on silage quality at low temperatures on the Tibetan Plateau. Anim Sci J 88:17221729. doi: 10.1111/asj.12852

50. Wanga CF, Muhammada AUR, Liua ZY, Huangb BZ, Cao BH. 2016. Effects of ensiling time on banana pseudo-stem silage chemical composition, fermentation and in sacco rumen degradation. J Anim Plant Sci 26: 339346.

51. Zahiroddini H, Baah J, Absalom W, Mcallister TA. 2004. Effect of an inoculant and hydrolytic enzymes on fermentation and nutritive value of whole crop barley silage. Anim Feed Sci Tech 117: 317-330. doi: 10.1016/j.anifeedsci.2004.08 .013

52. Zhang Y, Zhu L, Dong P, Liang R, Mao Y, Qiu S, Luo X. 2018. Bioprotective potential of lactic acid bacteria: Effect of Lactobacillus sakei and Lactobacillus curvatus on changes of the microbial community in vacuumpackaged chilled beef. Asian Austral J Anim 31: 585-594. doi: 10.5713/ ajas. 17.0540 